\title{
CLINICAL PROFILE AND OUTCOME OF CHILDREN WITH SEPSIS IN A TERTIARY CARE CENTRE IN EASTERN NEPAL: A PROSPECTIVE OBSERVATIONAL STUDY
}

\author{
Mukesh Bhatta ${ }^{1 *}$, Shyam Prasad Kafle ${ }^{1}$, Basant Rai $i^{1}$, Rejeena Subedi ${ }^{2}$
}

\begin{abstract}
Affiliation
1. Assistant Professor, Department of Paediatrics and Adolescent Medicine, BPKIHS, Dharan, Nepal.

2. Lecturer, Department of Child Health Nursing, Hamro School of Nursing, Biratnagar
\end{abstract}

\section{ARTICLE INFO}

Received : 20 July, 2021

Accepted : 12 December, 2021

Published : 21 February, 2022

(C) Authors retain copyright and grant the journal right of first publication with the work simultaneously licensed under Creative Commons Attribution License CC - BY 4.0 that allows others to share the work with an acknowledgment of the work's authorship and initial publication in this journal.

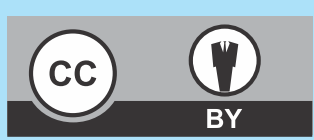

ORA 275

DOI: https://doi.org/10.3126/bjhs.v6i3.43200

\author{
* Corresponding Author \\ Dr. Mukesh Bhatta \\ Assistant Professor \\ Department of Paediatrics and Adolescent Medicine \\ BP Koirala Institute of Health Sciences, Dharan Nepal. \\ Email:mukacebhatta@gmail.com \\ ORCID: https://orcid.org/0000-0003-4742-5826
}

\section{Citation}

Clinical Profile and Outcome of Children with Sepsis in a Tertiary Care Centre in Eastern Nepal: a Prospective Observational Study. Mukesh Bhatta, Shyam Prasad Kafle, Basant Rai, Rejeena Subedi. BJHS 2021;6(3)16. 1595 - 1600.

\begin{abstract}
\section{Introduction}

Sepsis is a major cause of mortality in children. Understanding the clinical profile of sepsis helps in early diagnosis, treatment and prognostication of the patients.
\end{abstract}

\section{Objectives}

This study was done with an objective to assess the clinical features, disease course, etiology and outcome of children diagnosed with sepsis.

\section{Methodology}

A prospective observational study was conducted over a period of six months among 43 children of age group 1 month to 14 years of age admitted to the Pediatric Intensive Care unit with a diagnosis of sepsis. Convenience sampling technique was used. The patients were enrolled at admission and daily follow up was done till discharge. Clinical details and outcome were recorded and analyzed through Statistical Package for Social Science version 20.

\section{Result}

Out of 43 patients enrolled, $58 \%$ were males. The median age of the patients was 3 years (Inter Quartile Range 1, 10). Respiratory distress was the most common presenting clinical feature. Severe pneumonia (37\%) was the most common cause. In this study, 22 (51.2\%) patients died. Factors like presence of prior comorbidity, septic shock, Acute Respiratory distress syndrome, Multiple Organ Dysfunction Syndrome, severe sepsis, abnormal finding on chest $\mathrm{X}$ ray, hyperlactatemia, metabolic acidosis, ionotropes and Mechanical ventilation use were higher in the Nonsurvivor group as compared to the survivor group.

\section{Conclusion}

This study showed increased mortality inpatients having prior comorbidity, septic shock, Acute Respiratory distress syndrome, Multiple Organ Dysfunction Syndrome, severe sepsis, an abnormal finding on chest $X$ ray, hyperlactatemia, metabolic acidosis, use of ionotropes and use of Mechanical ventilation.

\section{KEYWORDS}

Disseminated intravascular coagulation, multiple organ failure, respiratory distress syndrome, septic Shock, systemic inflammatory response syndrome. 


\section{INTRODUCTION}

Sepsis involves a systemic inflammatory response syndrome (SIRS) in presence of infection, leading to septic shock and multi-organ system dysfunction. ${ }^{1,2}$ Most deaths caused by infections are due to sepsis.,

Sepsis is the most common cause of death in children worldwide..$^{5-8}$ Its mortality rate in children in developing countries is higher than fifty percent. ${ }^{9-12}$ The varied clinical presentation of sepsis and unavailability of a definitive test remains a big challenge, hence early recognition and treatment can be life-saving in developed and predeveloped countries. ${ }^{13,14}$ Knowing the clinical profile and outcome of sepsis in children will help in early recognition, better management, prognostication and timely prevention of complications.

The study was done with an objective of assessing the clinical profile, including the presenting clinical features, laboratory work up, etiology, treatment, response to treatment and final outcome.

\section{METHODOLOGY}

This was a Prospective observational study carried out at the Pediatric Intensive Care Unit (PICU) of B.P. Koirala Institute of Health Sciences (BPKIHS). Data collection was done over a period of six months from September 2020 to February 2021. The ethical clearance was obtained from the Institutional Review Committee (IRC) BPKIHS (Ref no. $57 / 077 / 078-I R C$ dated on $28^{\text {th }}$ August 2020), and informed written consent was obtained from the parents in local language before each enrolment. Patients from 1 month to 14 years of age admitted to the PICU of BPKIHSwith a diagnosis of sepsis by clinical and/or laboratory parameters, and whose parents gave consent were included in the study. However, children with a PICU stay of less than six hours, those with a surgical cause (pre-operative or post-operative) of sepsis like acute appendicitis, blunt trauma abdomen, ulcer perforation, intestinal obstruction, trauma, or those who have had inpatient treatment received in other centre for more than 3 days were excluded from the study. Similarly patients who Left Against Medical Advice (LAMA) and those children whose parents refused to give consent were also excluded from the study. The diagnosis of sepsis, SIRS, septic shock, severe sepsis, Multiple Organ Dysfunction Syndrome (MODS) and Acute Respiratory Distress Syndrome (ARDS) was based on the 2005 International Pediatric Sepsis Consensus Conference (IPCC) criteria., ${ }^{1,2}$

The sample size was 43.

The sample size was calculated using the following formula Based on a previous study by Kaur $\mathrm{G}$ et al, the proportion of patients with complication was $58 \%{ }^{15}$

$$
\begin{aligned}
& p=58 \% \\
& q=100-p \\
& q=42 \%
\end{aligned}
$$

Taking permissible error, $L=20 \%$ of $p$

$$
L=11.6 \%
$$

Using one sample formula, $\mathrm{n}_{0}=\mathrm{Z}^{2} \mathrm{pq} / \mathrm{L}^{2}$

$Z$ at $95 \%$ confidence interval $=1.96$

$$
\begin{aligned}
& \mathrm{n}_{\mathrm{o}}=\frac{1.96 \times 1.96 \times 58 \times 42}{11.6 \times 11.6} \\
& \mathrm{n}_{\mathrm{o}}=70
\end{aligned}
$$

$\mathrm{N}=85$ (prevalence of sepsis of age group 1 month to 14 years in the last one year)

Corrected sample size, $\mathrm{n}=\mathrm{n}_{0}$

$$
\begin{aligned}
& 1+n_{0} / N \\
& n=39
\end{aligned}
$$

Adding $10 \%$ of non-responders, final sample size $=39+10 \%$ of 39

$$
n=43
$$

\section{So, the final sample size was 43.}

Convenience sampling technique was used. The patients got enrolled from the day of admission in PICU, and followed up every day till discharge/death. The relevant demographic and clinical data, including age, gender, residence, clinical manifestations, laboratory parameters, treatment used, duration of treatment, duration of PICU stay and final outcome were recorded and entered in a predesigned proforma. The final outcome was defined as survivors and Non-survivors. The Data obtained were entered into the computer using Microsoft Excel program and statistical analysis done using Statistical Package for Social Sciences (SPSS) version 20 software. Descriptive statistics was used to analyze the data like mean, median and standard deviation (SD).Chi-square test was used for analysis of categorical data and association between the variables. Fisher's exact test and continuity correction was used as per the need of data. Quantitative data was compared using student $t$ test or Mann-Whitney $U$ test as per the need. After analysis of data, the results were presented through tabulations and charts. Clinical, laboratory and treatment parameter which distinguished survivors from non survivors were presented through tabulations.

\section{RESULTS}

This study was done among 43 children (aged 1 month to 14 years) diagnosed with sepsis. In this study, there were 25 (58.1\%) males and $18(41.9 \%)$ females. Thirty one (72\%) patients were from Terai region, while 12 (28\%) were from Hilly region. The median age of the patients was three years (IQR 1, 10). The median age among the non-survivors was 2 years (IQR $0.6,10)$ while that of the survivors was 4 years (IQR 1, 10.5). Also, the median age between the nonsurvivors and survivors was comparable $(p=0.62)$. The gender distribution was similar between the non-survivor and survivor group $(p=0.89)$.

In this study, 22 (51.2\%) patients died while 21 (48.8\%) survived and got discharged. The most common etiology for sepsis was severe pneumonia, seen in 16 (37\%) patients, while eight $(18.6 \%)$ had Gastrointestinal tract infection, seven (16.3\%) Central nervous system infection, four $(9.3 \%)$ skin infection and two (4.6\%) had bone and joint infection. The patients presented with different clinical features. Respiratory distress was the most common presenting clinical feature. The different clinical manifestations along with their frequency is given in Table 1. 
Table 1: Clinical manifestations

\begin{tabular}{|l|c|}
\hline Clinical Manifestation & Frequency (\%) \\
\hline Respiratory distress & $41(95)$ \\
\hline Fever & $35(81)$ \\
\hline Vomiting & $32(75)$ \\
\hline Seizure & $24(56)$ \\
\hline Altered sensorium & $18(42)$ \\
\hline Cough & $15(35)$ \\
\hline Raised Intracranial pressure & $15(35)$ \\
\hline Headache & $14(33)$ \\
\hline Status epilepticus & $11(25)$ \\
\hline Diarrhoea & $7(16)$ \\
\hline Oliguria & $3(7)$ \\
\hline Hematuria & $2(5)$ \\
\hline Congestive Cardiac Failure & $1(2.5)$ \\
\hline
\end{tabular}

Twenty Seven patients (62.8\%) had a Glasgow Coma Scale (GCS) score above 10 on presentation, while $16(37.2 \%)$ had a GCS score below 10 on presentation. However, the distribution of GCS score was similar in both non-survivor and survivor groups $(p=0.25)$. The time gap between hospitalization and PICU admission (median/IQR), and duration of PICU stay (median/IQR), were comparable among the Non-survivor and survivor groups ( $p=0.95$ and $p=0.15$ respectively). It was also observed that the number of patients having some form of prior comorbidity (like cerebral palsy, genetic syndromes, blood dyscrasias and severe acute malnutrition), septic shock, severe sepsis, ARDS, MODS and Disseminated Intravascular Coagulation (DIC) was higher in the non-survivor group as compared to the survivor group. However, the presence of coagulopathy and Acute Kidney injury (AKI) were comparable in both the groups. The distribution of various clinical characteristics among the survivors and non-survivors are presented in Table 2.

\begin{tabular}{|c|c|c|c|c|}
\hline Characteristics & $\begin{array}{l}\text { Non- } \\
\text { survivor }\end{array}$ & Survivor & $\begin{array}{l}\text { Total, } \\
\text { n (\%) }\end{array}$ & $P$ value \\
\hline $\begin{array}{l}\text { Median (IQR) time lag (hours) } \\
\text { between hospitalization and } \\
\text { PICU admission }\end{array}$ & $\begin{array}{r}10 \\
(4.5,48)\end{array}$ & $\begin{array}{r}17 \\
(4.8,48)\end{array}$ & & $0.95^{*}$ \\
\hline $\begin{array}{l}\text { Median (IQR) duration (days) } \\
\text { of PICU stay }\end{array}$ & $4(7,18.5)$ & $\begin{array}{r}3.5 \\
(3.6,11.5)\end{array}$ & & $0.15^{*}$ \\
\hline Prior comorbidity, n (\%) & $10(23.2)$ & $1(2.3)$ & $11(25.6)$ & $0.002^{* *}$ \\
\hline $\begin{array}{l}\text { Acute Respiratory Distress } \\
\text { Syndrome, } n(\%)\end{array}$ & $8(18.6)$ & $1(2.3)$ & $9(20.9)$ & $0.011^{* *}$ \\
\hline Septic shock, n (\%) & $21(48.8)$ & $13(30.2)$ & $34(79.1)$ & $0.007^{* *}$ \\
\hline Severe sepsis, $n(\%)$ & $22(51.2)$ & $6(13.9)$ & $28(65.1)$ & $<0.001^{* *}$ \\
\hline $\begin{array}{l}\text { Multiple Organ Dysfunction } \\
\text { Syndrome, } \mathrm{n}(\%)\end{array}$ & $20(46.5)$ & $4(9.3)$ & $24(55.8)$ & $<0.001^{* *}$ \\
\hline $\begin{array}{l}\text { Disseminated Intravascular } \\
\text { Coagulation, } n(\%)\end{array}$ & $13(30.2)$ & $3(7)$ & $16(37.2)$ & $0.002^{* *}$ \\
\hline Coagulopathy, n (\%) & $10(23.3)$ & $4(9.3)$ & $14(32.6)$ & $0.065^{* *}$ \\
\hline Acute Kidney Injury, n (\%) & $7(16.3)$ & $6(13.9)$ & $13(30.2)$ & $0.82 \dagger$ \\
\hline TOTAL & $22(51.2)$ & $21(48.8)$ & & \\
\hline
\end{tabular}

Blood culture was positive for organisms in five patients (11.6\%). Staphylococcus aureus was the most common organism isolated. However, the yield of organism in culture of body fluids and specimens was similar in both the survivor $\{6(14 \%)\}$ and non-survivor groups $\{5(11.6 \%)\}$ $(p=0.66)$. The details of organisms isolated in Blood, urine, Cerebro Spinal Fluid (CSF), Pleural fluid, Endotracheal Tube (ET) tip, and Central venous Pressure (CVP) Catheter tip is shown in Table 3.

\begin{tabular}{|c|c|c|c|c|c|c|c|}
\hline Organism & $\begin{array}{l}\text { Blood } \\
\text { n (\%) }\end{array}$ & $\begin{array}{l}\text { Urine } \\
n(\%)^{\circ}\end{array}$ & \begin{tabular}{|c|} 
CSF \\
$n(\%)^{*}$
\end{tabular} & \begin{tabular}{|l} 
Pleural \\
fluid \\
$n(\%)^{*}$
\end{tabular} & $\begin{array}{l}\text { ET tip } \\
n(\%)^{*}\end{array}$ & $\begin{array}{l}\text { CVP } \\
\text { catheter } \\
\text { tipn(\%)* }\end{array}$ & $\begin{array}{l}\text { Total } \\
n(\%)^{*}\end{array}$ \\
\hline $\begin{array}{l}\text { Staphylococcus } \\
\text { aureus }\end{array}$ & $2(4.7)$ & & $1(2.3)$ & & & $2(4.7)$ & $5(11.6)$ \\
\hline $\begin{array}{l}\begin{array}{l}\text { Pseudomonas } \\
\text { aeuroginosa }\end{array} \\
\end{array}$ & $1(2.3)$ & & & & $1(2.3)$ & & $2(4.7)$ \\
\hline Acinetobacter & & & & & $1(2.3)$ & & $1(2.3)$ \\
\hline Klebsiellapneumoniae & $1(2.3)$ & $1(2.3)$ & & $1(2.3)$ & & & $3(7)$ \\
\hline \begin{tabular}{|l|} 
Escherichia coli \\
\end{tabular} & & $1(2.3)$ & & & & & $1(2.3)$ \\
\hline Enterococcus faecalis & $1(2.3)$ & & & & & & $1(2.3)$ \\
\hline Yeast & & & & & $1(2.3)$ & & $1(2.3)$ \\
\hline Total $n(\%)^{*}$ & $5(11.6)$ & $2(4.7)$ & 1 (2.3) & $1(2.3)$ & $3(7)$ & $2(4.7)$ & \\
\hline
\end{tabular}

In this study, hyponatremia was seen in 18 (42\%) patients while hypernatremia was seen in two $(4.7 \%)$ patients. Similarly, hypokalemia was seen in six (14\%) patients while hyperkalemia was seen in seven $(16.3 \%)$ patients. Three (7\%) patients had hypoglycaemia. The distribution of these biochemical parameters were similar in both the survivor and non-survivor groups. Similarly, non-survivors didn't differ from survivors in terms of platelet count, haemoglobin level, total leukocyte count, serum urea and creatinine.

An abnormal Arterial blood gas (ABG) was seen in 37 (86\%) cases. Metabolic acidosis was the most common acid-base abnormality, seen in 36 (83.7\%) patients. The median (IQR) lactate level (mmol/litre) in Non-survivors $\{4(2.2,5)\}$ was higher than that of the Survivors $\{1.5(0.9,2)\}(p<0.001)$. Similarly, 32 (75\%) patients had hyperlactatemia while 10 (24\%) developed respiratory acidosis. On further analysis, the number of patients with hyperlactatemia and metabolic acidosis were significantly higher in the non-survivor group as compared to the survivor group. Similarly an abnormal chest $X$ ray (presence of pneumonic consolidation or pleural effusion or features suggestive of ARDS) was seen in 28 (65\%) patients. The presence of abnormality on chest X-ray was found to be higher in the non-survivor group as compared to the survivor group. The details of these blood gas and chest $\mathrm{x}$-ray abnormalities are given in table 4 .

\begin{tabular}{|c|c|c|c|c|c|}
\hline \multicolumn{2}{|l|}{ Characteristics } & $\begin{array}{c}\text { Non-survivor, } \\
\mathrm{n}(\% \text { of } \\
\text { total) }\end{array}$ & $\begin{array}{c}\text { Survivor, } \\
\mathbf{n}(\% \text { of } \\
\text { total) }\end{array}$ & $\begin{array}{l}\text { Total, } \\
\text { n (\% of } \\
\text { total) }\end{array}$ & P value \\
\hline Hyperlactatemia & Present & $21(49)$ & $11(25.6)$ & $32(74.4)$ & $0.001^{*}$ \\
\hline Metabolic acidosis & Present & $22(51.2)$ & $14(32.6)$ & $36(83.7)$ & $0.003^{*}$ \\
\hline Abnormal Chest X Ray & Present & $18(42)$ & $10(23.3)$ & $28(65.1)$ & $0.019^{*}$ \\
\hline \multirow{2}{*}{$\begin{array}{l}\text { Number of } \\
\text { antibiotics used }\end{array}$} &. & $12(27.9)$ & $11(25.6)$ & $23(53.5)$ & \multirow[t]{2}{*}{$0.64^{* *}$} \\
\hline & $>3$ & $9(20.9)$ & $11(25.6)$ & $20(46.5)$ & \\
\hline $\begin{array}{l}\text { Requirement of } \\
\geq 2 \text { fluid bolus }\end{array}$ & Present & $21(48.8)$ & $16(37.2)$ & $37(86)$ & $0.07^{*}$ \\
\hline Ionotrope use & Present & $21(48.8)$ & $10(23.3)$ & $31(72.1)$ & $<0.001^{*}$ \\
\hline \multirow{2}{*}{$\begin{array}{l}\text { Duration of ionotrope } \\
\text { use (hours) }\end{array}$} & $\leq 48$ & 5 (11.6) & $9(20.9)$ & $14(32.6)$ & \multirow[t]{2}{*}{$0.71^{*}$} \\
\hline & $>48$ & $5(11.6)$ & $12(27.9)$ & $17(39.5)$ & \\
\hline $\begin{array}{l}\text { Mechanical } \\
\text { ventilation use }\end{array}$ & Present & $20(46.5)$ & $6(13.9)$ & $26(60.5)$ & $<0.001^{*}$ \\
\hline \multirow{2}{*}{$\begin{array}{l}\text { Duration of Mechanical } \\
\text { ventilation }\end{array}$} & $>5$ days & $18(41.9)$ & $1(2.3)$ & $19(44.2)$ & \multirow[t]{2}{*}{$<0.001^{*}$} \\
\hline & $\leq 5$ days & $2(4.6)$ & $5(11.6)$ & $7(16.3)$ & \\
\hline Immediatecomplications & Present & $22(51.2)$ & $11(25.6)$ & $33(76.7)$ & $<0.001^{*}$ \\
\hline TOTAL & & 22 (51.2) & $21(48.8)$ & & \\
\hline
\end{tabular}

*:Fisher's exact test, ${ }^{*}$ : Chi-square test 
The patients were treated with supplemental oxygen, intravenous fluids, ionotropes, intravenous antibiotics and other supportive therapies, wherever indicated. Steroids were used in nine $(21 \%)$ patients, while $23(53 \%)$ received blood products in some form. Antibiotics in some form (oral or parenteral) were received by 23 patients $(53.5 \%)$ within 3 days prior to the hospital visit. The number of antibiotics used were comparable in both the survivor and nonsurvivor group $(p=0.64)$. Likewise, the use of ionotropes was significantly higher in the non- survivor group $(p<0.001)$. However, the duration of ionotrope use (whether used for $\leq 48$ hours or more than 48 hours) was comparable in the survivor and non-survivor group $(p=0.71)$. It was also observed that use of Mechanical Ventilation (MV) and duration of mechanical ventilation use for less than or equal to 5 days were significantly higher in the non-survivor group. Ventilator Associated pneumonia (VAP) was seen in eight $(18.6 \%)$ patients. Also, the patients who died at a significantly higher rate of complications (including Ventilator Associated pneumonia (VAP), deep venous thrombosis, pneumothorax, pressure sore, thrombophlebitis, septic arthritis, empyema, hepatitis and hepatic encephalopathy). The details of the different treatment modalities used is given in table 4.

\section{DISCUSSION}

The median age of patients in our study was 3 years which was similar to other studies. ${ }^{15-18}$ Study done by Ghimire JJ et al however, showed a higher median age around 7 years. ${ }^{19}$ The reason for younger children being more infected can be attributed to the lower immunity in that age group. There was a slight male preponderance in this study which is consistent to the findings of other studies. ${ }^{15-23}$

We observed a mortality rate of $51 \%$ in our study, similar to the observations made by Kaur G et al. ${ }^{15}$ However Studies done in developed countries by other authorshad a lower mortality rate (10-20\%). ${ }^{16-18,20,21,23}$ The higher mortality rate in our setup could be due to multiple factors like delay in hospital arrival, poverty, lack of proper infrastructure and skilled manpower. Nearly a quarter of the patients in this study had some form of prior comorbidity, and this was higher in the non-survivor group. Similar are the findings given by Pedro Tda C et al and Vila Perez D et al. ${ }^{16,20}$ However, Jaramillo Bustamante JC et al and Humoodi $\mathrm{MO}$ et al observed a higher incidence of comorbidity (50-75\%) in their patients. ${ }^{18,22}$

The most common etiology of sepsis in our study was pneumonia, similar to what most of the other authors observed. ${ }^{18-20,22,23}$ Dissimilar to this, was the finding of Boeddha NP et al, in which the most common etiology of sepsis was fever without focus. ${ }^{21}$ The median duration of PICU stay (4 days) in this study was lesser than what Ghimire JJ et al ( 6 days) and Humoodi MO et al ( 8 days) observed. ${ }^{19,22}$

The incidence of AKI was much higher (30\%) in our study as compared to the findings of Kaur G et al ( $2 \%-3.5 \%)$ and Pedro Tda C et al (2\%). ${ }^{15,16}$ However, the presence of AKI was comparable in both the non-survivor and survivor group in these studies. In contrary, Vila Perez D et al in their study, observed that AKI was significantly higher in the nonsurvivor group. ${ }^{20}$ Similarly, the incidence of Congestive Cardiac failure (CCF) in this study (2.3\%) was comparable to the findings of Kaur G et al(1\%-4\%) and Pedro Tda C et al. ${ }^{15,16}$ Also, the presence of CCF was similar in the survivors and non-survivor group. However, Vila Perez D et al in their study, observed a significant association between CCF and mortality. ${ }^{20}$

Blood culture positivity for bacteria was seen in nearly $12 \%$ cases in this study; reason for this low yield being indiscriminate antibiotic use prior to hospital arrival. In contrary, other studies had a higher yield (20-51\%) of bacteria in blood. ${ }^{16-18,21,22}$ Staphylococcus aureus was the most common organism yielded in this study while Vila Perez D et al and Boeddha NP et al reported Neisseria meningitidis as the most common organism while Jaramillo Bustamante JC et al reported gram negative bacilli as the predominant bacteria. ${ }^{18,20,21}$ However none of the above mentioned studies mentioned an association of blood culture positivity with mortality.

In this study, ARDS was seen in $20 \%$ of the patients, which was similar to the findings made by Xiao $\mathrm{C}$ et al. ${ }^{23}$ However, the incidence of septic shock was much lower (2.1-48\%) in other studies as compared to this study (79\%). . $^{15,18,24}$ In this study, the incidence of severe sepsis was $65 \%$. However, Pedro Tda C et al observed a higher incidence (89\%) of severe sepsis than our study while Jaramillo Bustamante JC et al and Wolfer $A$ et al reported a lower incidence of severe sepsis in their studies (1.6\%-25\%). ${ }^{16,18,24}$

The incidence of DIC in this study was nearly $60 \%$. Dissimilar to this, was the finding of Pedro Tda $\mathrm{C}$ et al, who reported a lesser incidence of DIC (1\%). ${ }^{16}$ Likewise, the presence of MODS in our study (56\%) was higher to that observed by Pedro Tda C et al, Jaramillo Bustamante JC et al and Vila Perez $D$ et al (4.3-43\%). ${ }^{16,18,20}$ The possible reasons for a higher incidence of DIC and MODS in our setup could be a delay in hospital arrival and/or inadequate critical care services. Nevertheless, the observation that the presence of severe sepsis, ARDS, MODS, DIC and septic shock was higher in the non-survivor group was similar to the studies done by Shime $\mathrm{N}$ et al, Jaramillo Bustamante JC et al, Ghimire JJ et al,and Vila Perez D et al. ${ }^{17-20}$

The use of mechanical ventilation was done in $60 \%$ of the patients in this study. Ghimire JJ et aland Vila Perez D et al also observed a similar rate of use of mechanical ventilation $(64-68 \%))^{19,20}$ Likewise the median duration of mechanical ventilation used in this study (3.5 days) was similar to the study done by Ghimire JJ et aland Xiao C et al. ${ }^{19,23}$ Also, the number of patients in whom ionotropes were used in this study (79\%) were comparable to the findings made by Ghimire JJ et al. ${ }^{19}$

\section{CONCLUSION}

This study showed that younger children are vulnerable to develop sepsis. Pneumonia is the most common etiology. Most of the patients who develop sepsis presented in septic shock. The presence of prior comorbidity, severe sepsis, ARDS, MODS, DIC, hyperlactatemia, abnormality on chest Xray and presence of metabolic acidosis were higher in those 
who died. So, in view of these findings, utmost care and proper management should be instituted early in those who develop these features. Likewise, prognostication and counselling to the parents can be done based on the above findings.

\section{RECOMMENDATIONS}

In view of the above findings, utmost care and proper management should be instituted early in those patients with sepsis who have underlying comorbidity, severe sepsis, ARDS, MODS, DIC, hyperlactatemia, abnormality on chest $X$ ray and presence of metabolic acidosis. Likewise, prognostication and counselling to the parents can be done based on the above findings.

\section{LIMITATIONS OFTHE STUDY}

This study has certain limitations. Smaller sample size is one of the limitations of this study. Also, some patients had received treatment prior to arrival at our centre, this could have masked many clinical and laboratory findings. Some patients arrived at the emergency with sepsis, while some developed sepsis during the hospital stay. This created some disparity in the hospital course. Similar study, with a larger sample size could be done in the future to get a clearer picture.

\section{ACKNOWLEDGEMENT}

The authors are thankful to those patients and their parents who had given consent to participate in this study

\section{CONFLICT OF INTEREST}

None

\section{FINANCIAL DISCLOSURE}

None

\section{REFERENCES}

1. Goldstein B, Giroir B, Randolph A; International Consensus Conference on Pediatric Sepsis. International pediatric sepsis consensus conference: definitions for sepsis and organ dysfunction in pediatrics. PediatrCrit Care Med. 2005 Jan;6(1):2-8. doi: 10.1097/01.PCC.0000149131.72248.E6. PMID: 15636651.

2. Gebara BM. Values for systolic blood pressure. PediatrCrit Care Med. 2005 Jul;6(4):500; author reply 500-1. doi: 10.1097/01.pcc. 0000164344.07588.83. PMID: 16003219

3. Kissoon N, Carcillo JA, Espinosa V, Argent A, Devictor D, Madden M, Singhi S, van der Voort E, Latour J; Global Sepsis Initiative Vanguard Center Contributors. World Federation of Pediatric Intensive Care and Critical Care Societies: Global Sepsis Initiative. PediatrCrit Care Med. 2011 Sep;12(5):494-503. doi: 10.1097/PCC.0b013e 318207096 c. PMID: 21897156.

4. Watson RS, Carcillo JA. Scope and epidemiology of pediatric sepsis.PediatrCrit Care Med. 2005 May;6(3 Suppl):S3-5. doi: 10.1097/01.PCC.0000161289.22464.C3. PMID: 15857554.

5. Bahl R, Martines J, Ali N, Bhan MK, Carlo W, Chan KY, Darmstadt GL, Hamer DH, Lawn JE, McMillan DD, Mohan P, Paul V, Tsai AC, Victora CG, Weber MW, Zaidi AK, Rudan I. Research priorities to reduce global mortality from newborn infections by 2015. Pediatr Infect Dis J. 2009 Jan;28(1 Suppl):S43-8. doi: 10.1097/INF.0b013e31819588d7. PMID: 19106763

6. Carcillo JA. Reducing the global burden of sepsis in infants and children: a clinical practice research agenda. PediatrCrit Care Med. 2005;6(Suppl):S157-64. doi: 10.1097/01.PCC.000016157436857.CA.

7. Watson RS, Carcillo JA, Linde-Zwirble WT, Clermont G, Lidicker J, Angus DC. The epidemiology of severe sepsis in children in the United States. Am J RespirCrit Care Med. 2003 Mar 1;167(5):695-701. doi: 10.1164/rccm.200207-6820C. Epub 2002 Nov 14. PMID: 12433670.

8. Wiens MO, Kumbakumba E, Kissoon N, Ansermino JM, Ndamira A, Larson CP. Pediatric sepsis in the developing world: challenges in defining sepsis and issues in post-discharge mortality. ClinEpidemiol. 2012;4:319-25. doi: 10.2147/CLEP.S35693. Epub 2012 Nov 22. PMID 23226074; PMCID: PMC3514048.

9. Sarthi M, Lodha R, Vivekanandhan S, Arora NK. Adrenal status in children with septic shock using low-dose stimulation test. PediatrCrit Care Med. 2007 Jan;8(1):23-8. doi: 10.1097/01.pcc. 0000256622.63135.90. PMID: 17251878
10. Ruth A, McCracken CE, Fortenberry JD, Hall M, Simon HK, Hebbar KB. Pediatric severe sepsis: current trends and outcomes from the Pediatric Health Information Systems database. PediatrCrit Care Med. 2014 Nov;15(9):828-38. doi: 10.1097/PCC. 0000000000000254. PMID: 25226500.

11. Hartman ME, Linde-Zwirble WT, Angus DC, Watson RS. Trends in the epidemiology of pediatric severe sepsis*.PediatrCrit Care Med. 2013 Sep;14(7):686-93. doi: 10.1097/PCC.0b013e3182917fad. PMID: 23897242.

12. Bryce J, Boschi-Pinto C, Shibuya K, Black RE; WHO Child Health Epidemiology Reference Group. WHO estimates of the causes of death in children.Lancet. 2005 Mar 26-Apr 1;365(9465):1147-52. doi: 10.1016/S0140-6736(05)71877-8. PMID: 15794969.

13. Han YY, Carcillo JA, Dragotta MA, Bills DM, Watson RS, Westerman ME, Orr RA. Early reversal of pediatric-neonatal septic shock by community physicians is associated with improved outcome. Pediatrics. 2003 Oct;112(4):793-9. doi: 10.1542/peds.112.4.793. PMID: 14523168

14. Oliveira CF, Nogueira de Sá FR, Oliveira DS, Gottschald AF, Moura JD, Shibata AR, Troster EJ, Vaz FA, Carcillo JA. Time- and fluid-sensitive resuscitation for hemodynamic support of children in septic shock: barriers to the implementation of the American College of Critical Care Medicine/ Pediatric Advanced Life Support Guidelines in a pediatric intensive care unit in a developing world. PediatrEmerg Care. 2008 Dec;24 (12):810-5. doi: 10.1097/PEC.0b013e31818e9f3a. PMID: 19050666.

15. Kaur G, Vinayak N, Mittal K, Kaushik JS, Aamir M. Clinical outcome and predictors of mortality in children with sepsis, severe sepsis, and septic shock from Rohtak, Haryana: A prospective observational study. Indian J Crit Care Med. 2014 Jul;18(7):437-41. doi: 10.4103/09725229.136072. PMID: 25097356; PMCID: PMC4118509.

16. Pedro Tda C, MorcilloAM, Baracat EC. Etiology and prognostic factors of sepsis among children and adolescents admitted to the intensive care unit. Rev Bras TerIntensiva. 2015 Jul-Sep;27(3):240-6. doi: 10.5935/0103507X.20150044. PMID: 26465245; PMCID: PMC4592118.

17. Shime N, Kawasaki T, Saito O, Akamine Y, Toda Y, Takeuchi M, Sugimura H, Sakurai Y, lijima M, Ueta I, Shimizu N, Nakagawa S. Incidence and risk factors for mortality in paediatric severe sepsis: results from the national paediatric intensive care registry in Japan. Intensive Care Med. 2012 Jul;38(7):1191-7. doi: 10.1007/s00134-012-2550-z. Epub 2012 Apr 18. PMID: 22527068 
18. Jaramillo-Bustamante JC, Marín-Agudelo A, Fernández-Laverde M, Bareño-Silva J. Epidemiology of sepsis in pediatric intensive care units: first Colombian multicenter study. PediatrCrit Care Med. 2012 Sep;13 (5):501-8. doi: 10.1097/PCC.0b013e31823c980f. PMID: 22460772.

19. Ghimire JJ, Gami FC, Thapa SB. Clinical, Demographic Profile and Outcome of Children Admitted in PICU with A Diagnosis of Severe Sepsis and Septic Shock. Journal of Medical Science and Clinical Research. 2017 Dec;05(12): 31470-31474. DOI: 10.18535/jmscr /v5i12.40.

20. Vila Pérez D, Jordan I, Esteban E, García-Soler P, Murga V, Bonil V, Ortiz I, Flores C, Bustinza A, Cambra FJ. Prognostic factors in pediatric sepsis study, from the Spanish Society of Pediatric Intensive Care. Pediatr Infect Dis J. 2014 Feb;33(2):152-7. doi: 10.1097/01.inf.0000435502.36996.72. PMID: 24413407.

21. Boeddha NP, Schlapbach LJ, Driessen GJ, Herberg JA, Rivero-Calle I, Cebey-López M, Klobassa DS, Philipsen R, de Groot R, Inwald DP, Nadel S, Paulus S, Pinnock E, Secka F, Anderson ST, Agbeko RS, Berger C, Fink CG, Carrol ED, Zenz W, Levin M, van der Flier M, Martinón-Torres F, Hazelzet JA, Emonts M; EUCLIDS consortium. Mortality and morbidity in community-acquired sepsis in European pediatric intensive care units: a prospective cohort study from the European Childhood Life-threatening Infectious Disease Study (EUCLIDS). Crit Care. 2018 May 31;22(1):143. doi: 10.1186/s13054018-2052-7. PMID: 29855385; PMCID: PMC5984383.
22. Humoodi MO, Aldabbagh MA, Salem MM, Al Talhi YM, Osman SM, Bakhsh M, Alzahrani AM, Azzam M. Epidemiology of pediatric sepsis in the pediatric intensive care unit of king Abdulaziz Medical City, Jeddah, Saudi Arabia. BMC Pediatr. 2021 May 7;21(1):222. doi: 10.1186/s12887-021-02686-0. PMID: 33962589; PMCID: PMC8103596.

23. Xiao C, Wang S, Fang F, Xu F, Xiao S, Li B, Zhang G, Luo X, Jiang J, Huang B, Chen Y, Chen J, Wang H, Yu J, Ren D, Ren X, Tang C. Epidemiology of Pediatric Severe Sepsis in Main PICU Centers in Southwest China. PediatrCrit Care Med. 2019 Dec;20(12):1118-1125. doi: 10.1097/ PCC. 0000000000002079 . PMID: 31261227

24. Wolfler A, Silvani P, Musicco M, Antonelli M, Salvo I; Italian Pediatric Sepsis Study (SISPe) group. Incidence of and mortality due to sepsis, severe sepsis and septic shock in Italian Pediatric Intensive Care Units: a prospective national survey. Intensive Care Med. 2008 Sep;34(9):1690-7. doi: 10.1007/s00134-008-1148-y. Epub 2008 May 24. PMID: 18500425. 